\title{
Investigation on the relationship of proline with wheat anti-drought under soil water deficits
}

\author{
Shao Hong-Bo ${ }^{\text {a,b,c,*}, \text { Chen Xiao-Yan }}{ }^{\text {d,g }}$, Chu Li-Ye ${ }^{c}$, Zhao Xi-Ning ${ }^{b, *}$, Wu Gang ${ }^{\text {h,* }}$, \\ Yuan Yong-Bing ${ }^{\mathrm{e}}$, Zhao Chang-Xing ${ }^{\mathrm{e}}$, Hu Zan-Min ${ }^{\mathrm{f}}$ \\ ${ }^{a}$ Key Laboratory of Molecular Biology, Bio-informatics College, Chongqing University of Posts \& Telecommunications, \\ Chongqing 400065, China \\ ${ }^{\mathrm{b}}$ Northwest A\&F University and Center of National Water-Saving and Irrigation at Yangling, \\ Centre of Soil and Water Conservation and Eco-Environmental Research, \\ The Chinese Academy of Sciences, Yangling 712100, China \\ ${ }^{\mathrm{c}}$ Biology Department, College of Molecular and Chemical Engineering, Qingdao University of Science and Technology, \\ Qingdao 266042, China \\ ${ }^{\mathrm{d}}$ Centre of Soil and Water Conservation and Eco-Environmental Research, The Chinese Academy of Sciences, \\ Yangling 712100, China \\ e Qingdao City Key Laboratory of Modern Agriculture Quality and Safety Engineering, Laiyang Agricultural University, \\ Qingdao 266109, China \\ ${ }^{\mathrm{f}}$ Institute of Genetics \& Developmental Biology, the Chinese Academy of Sciences, \\ Beijing 100101, China \\ g Graduate School of the Chinese Academy of Sciences, Beijing 100039, China \\ ${ }^{\mathrm{h}}$ State Key Laboratory of Urban and Regional Ecology, Research Center for Eco-environmental Sciences, \\ the Chinese Academy of Sciences, Beijing 100085, China
}

Received 11 June 2006; received in revised form 12 July 2006; accepted 10 August 2006

Available online 18 August 2006

\begin{abstract}
Proline (content) is closely with plant anti-drought, especially under soil water deficits. Many reports from crops and other plants have proved this. Wheat is the second important crop on the globe, whose research in this aspect of importance for food quality, safety, and yield in field. The related difference in physiological indicators and proline content for different soil water treatments among wheat with different genotypes is not clear, which has limited deep study of wheat anti-drought molecular biology and related anti-drought biotechnological breeding. Our current study was focused on the physiological relationship of proline and different genotype wheat anti-drought under soil water deficits. Main results showed that different wheat genotype had different soil water stress threshold. Pro content had closed relationship with soil water stress threshold and wheat anti-drought. Developmental course also impacted Pro content for different wheat genotypes.
\end{abstract}

(c) 2006 Elsevier B.V. All rights reserved.

Keywords: Wheat (Triticum aestivum L.); Genotypes; Proline; Anti-drought; Soil water deficits; Water-saving biology; Stress physiology; Physiological water-saving

\section{Introduction}

Humankind is dependent on crops for most of our food and feed, as well as for many other important plant materials. Cur-

Abbreviations: FC, field capacity; POD, peroxidase ;SODsuperoxide dismutase; CAT, catalase

* Corresponding authors. Tel.: +86 532 84022506; fax: +86 53284022757 .

E-mail addresses: shaohongbochu@126.com (S. Hong-Bo),

Xiningzhao@yahoo.com.cn (Z.Xi-Ning), wug@ rcees.ac.cn (W. Gang). rently crops occupy nearly one fifth of the planet's vegetated surface, by far the biggest imprint of man upon the planet and its landscapes. Cropping is also the world's largest source of employment and livelihood, with well over 1 billion small farmers in developing countries [1-3,18,31]. Drought is a worldwide problem, constraining global crop production and quality seriously. Water drives agricultural production in many parts of the world. Indeed, the "Green Revolution" was so successful in reducing hunger because the increased use of irrigation was one of the factors behind the successful increase in crop 
production. However, in the 21 st century, demand by industry, demand by urban populations and demands to maintain environmental flows and water quality will reduce the water available for irrigated agriculture. Moreover, emerging climate change is predicted to reduce rainfall and increase rainfall variability in many agricultural systems [4-9,26-32,60,78-80,85]. Thus, the issue for crop science is how to increase production with less water available for irrigation and less reliable rainfall that limits dryland agriculture in many parts of the world [10-14]. Drought is a complex physical-chemical process, in which many biological macromolecules and small molecules are involved, such as nucleic acids (DNA, RNA, microRNA), proteins, carbohydrates, lipids, hormones, ions, free radicals, mineral elements. In addition, drought is also related to salt stress, cold stress, high temperature stress, acid stress, alkaline stress, pathological reactions, senescence, growth, development, cell circle, UV-B damage, wounding, embryogenesis, flowering, signal transduction and so on [15-19,20-25,82,83]. Therefore, drought is connected with almost all aspects of biology. Currently, drought study has been one of the main directions in global plant biology and biological breeding. NSF in USA established the program of Plant Genome Functions Under Stresses in 1998, and strengthened it in 2000, and drafted it towards $2010[14,49]$. Just 2 months ago, European Commission, who once kept conservative to biotechnological breeding, constructed a big project: Plants for the Future: a European vision for Plant Biotechnology towards 2025, in which much is involved in resistance drought [13]. Many advances in relation to this hot topic, including molecular mechanism of anti-drought and corresponding biotechnological breeding have taken place [33-48,62,64-67,81-83]. Although the obtained transgenic crops (mainly, wheat) by different types of gene technology all exhibit drought resistance to some extent, they have some shortfalls related to agronomical performance and/or development $[3,6,19,26,32,43,45,46,48,60,62,65,81]$. These results imply that systemical, deeper, and comprehensive understanding of physiological mechanism of crops under drought stresses is not enough to manipulate the physiological regulatory mechanism and take advantage of full this potential for productivity, whose study is the bridge between molecular machinery of drought and anti-drought agriculture, because the performance of genetic potential of crops is expressed by physiological realization in fields [49-54,80-85]. Towards this aim, many promising methodologies appear, but they should also be linked with field practice $[1,10,23,28-30,36,46,60,61,68]$. Wheat is a staple food for more than $35 \%$ of the world population and wheat is also the second main grain crop in China, whose production status is directly related to social stability, Chinese survival and sustainable development $[25,38,52-59,79]$. With progressive global climate change and increasing shortage of water resources and worsening eco-environment, wheat production is influenced greatly $[3,8,11,12,15,18,25,26,31,35,39,42,44,60,73-80,85]$.

Some reports have been related to proline (content) relationship with wheat and other crop plant drought resistance, but the data related to the relationship in different genotypes of wheat have been lacking and contrary $[11,15,25,42,44$, 68-70,74], especially little is involved in such aspect of dif- ferent wheat genotypes [54-58]. It has been well known that osmotic regulators include many important small molecules such as potassium, soluble sugar, proline and betaine [2,5,6, $21,25,34,42,52,64,67,70,74,75,77]$. These small molecules are also important physiological indicators for evaluating osmotic adjustment ability [62-67,71-73,82-84] and drought resistance in wheat species and genotypes. To aim at making different wheat genotypes perform fully physiological potential under limited soil water conditions in fields, by selecting practical materials for direct breeding and establishing an efficient platform for deciphering molecular mechanisms of wheat drought resistance, we chose 10 promising wheat genotypes (field experiments have proved) as experimental materials, applied stimulation natural drought and potting cultivation methods, collected proline data of two growth stages (seedling stage and tillering stage) and primarily evaluated the relationship between their anti-drought and these genotypes and proline.

\section{Materials and methods}

\subsection{Plant materials}

Ten wheat genotypes (Xinong 9-1-1-13, Xinong-1, Xinong 32, Xinong 4-2, Xinong 9337-1, YB0738, Xiaobingcao 7, Jinmai 47, Yumai 49, Xiaoyan 22, and labeled 1-10, respectively) are provided kindly by Professor Zhang ZM from Yangling Breeding Center of National Wheat Engineering Research Center of China [55].

\subsection{Experimental fields}

The outward potting cultivation field is affiliated to experimental plots of State Key Laboratory of Soil Erosion and Dryland Farming, the Center of Soil and Water Conservation and Ecoenvironmental Research, Chinese Academy of Sciences. Pots are made of plastics, whose empty weight was $2 \mathrm{~kg}$ and the full pot weight was $24 \mathrm{~kg}$ according to [20]. The physical and chemical property of the selected soil is as follows: organic matter $11.5 \mathrm{mg} / \mathrm{g}$, total $\mathrm{N} 0.94 \mathrm{mg} / \mathrm{g}$, available $\mathrm{N} 122.2 \mathrm{mg} / \mathrm{kg}$, effective P $52.4 \mathrm{mg} / \mathrm{kg}$, available K $222.4 \mathrm{mg} / \mathrm{kg}$ [56].

\subsection{Experimental design}

Each genotype was conducted in three level soil water treatments controlled by weighting (75\% FC, 55\% FC, and $45 \%$ FC, respectively) according to [24], each of which is six times repeated and matched with one empty control, correspondingly $[57,58]$.

\subsection{Proline content measurement}

According to Gao [20], proline content in the wheat plant leaves of different genotypes was detested (flag leaves of different wheat genotypes at seedling stage and tilling stage). All the data were measured three times at the same time and the mean used for result analysis and discussion. 


\section{Results}

\subsection{Proline content comparison of 10 wheat genotypes at soil water deficits at seedling stage}

According to Fig. 1, under the condition of level 1 ( $75 \%$ FC), genotypes 2, 3, 4, 8 and 9 (A group) had higher Pro content. Genotype 2 had the highest content of Pro and genotype 8 the lowest among these five genotypes. Under the condition of level 2 (55\% FC), genotypes 1, 5 and 7 possessed higher content of Pro (B group). Genotype 5 exhibited the highest and 7 the lowest among the above genotypes. At level 3 (45\% FC), genotypes 6 and 10 expressed higher content of Pro (C group). Generally, half of the tested genotypes were classified into A group, which indicated that most wheat genotypes had the anti-drought performance under appropriate condition of soil water and further demonstrated that the drought resistance character was an accumulated one, needing one concerted environment in vivo for its better performance. Seemingly, genotypes 6 and 10 have the potential to be selected for planting and breeding in arid and semi-arid areas.

\subsection{Proline content comparison of 10 wheat genotypes at soil water deficits at tilling stage}

From Fig. 2, it was observed that under the condition of level 1, genotypes 7-9 had higher Pro content (A group). Genotypes

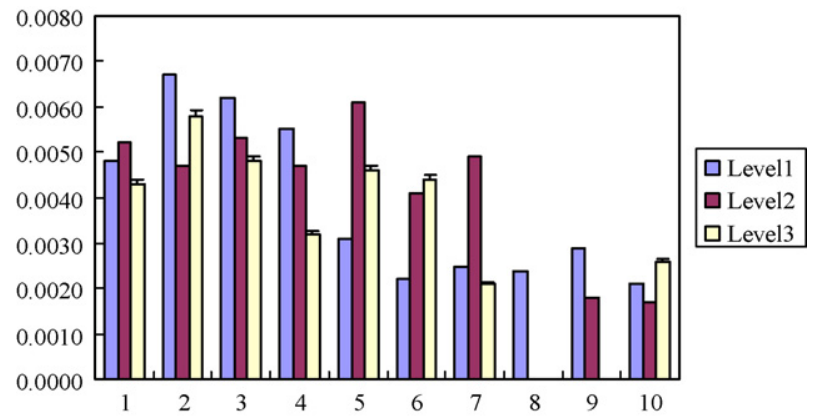

Fig. 1. Proline content $(\mu \mathrm{g} / \mathrm{g} \mathrm{dw})$ comparison of 10 wheat genotypes at soil water deficits at seedling stage (blue, red, and yellow color represents $75 \%$ FC (level 1), 55\% FC (level 2), 45\% FC (level 3), respectively. The below is the same).

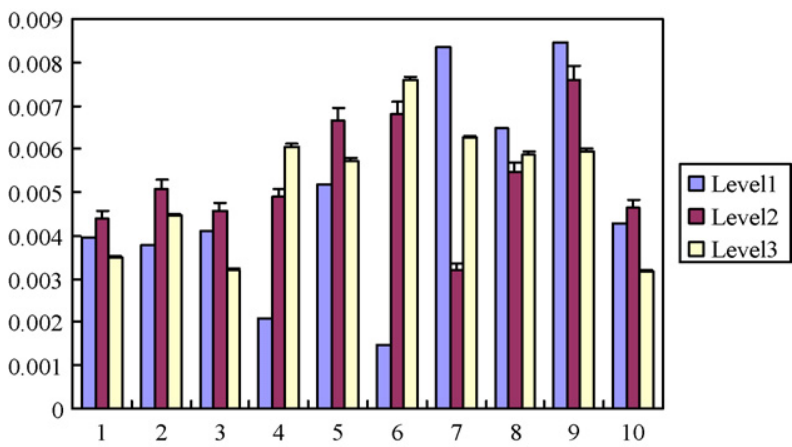

Fig. 2. Proline content $(\mu \mathrm{g} / \mathrm{g} \mathrm{dw})$ comparison of 10 wheat genotypes at soil water deficits at tilling stage.

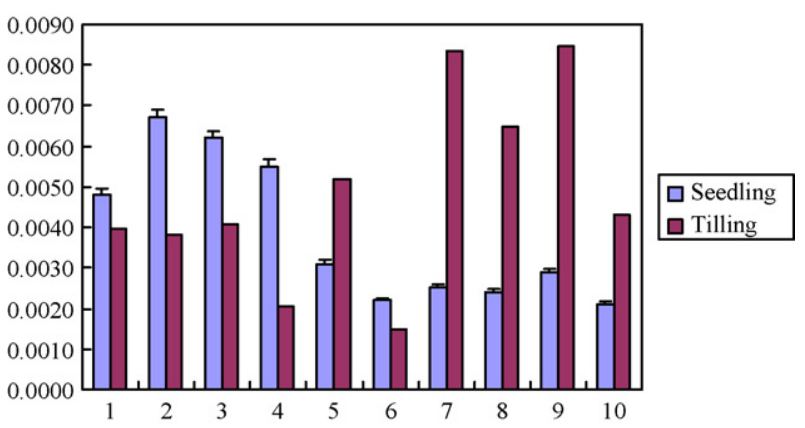

Fig. 3. The proline content $(\mu \mathrm{g} / \mathrm{g} \mathrm{dw})$ difference of 10 wheat genotypes for seedling and tilling stage under the condition of level 1.

7 and 9 had relatively higher Pro content of these three genotypes (A group). At level 2, genotypes 1-3, 5 and 10 (B group) exhibited higher Pro content. Genotype 5 had the highest Pro content in B group and genotype 1 the lowest Pro content of B group. At level 3, genotypes 4 and 6 (C group) had higher Pro content. Comparing Fig. 1with Fig. 2, it was found that different genotype wheat had their different soil water suitable levels and they might change with progressive growth and development for different wheat genotypes. In most cases, most wheat genotypes (nearly 50\%) could have higher potential to protect from soil water deficits regardless of developmental stages. From the viewpoint of application, genotype 6 is one better candidate for practice in arid and semi-arid zones in the world, which is in agreement with the above.

\subsection{Proline content difference of 10 wheat genotypes for seedling and tilling stage under the condition of level 1}

From Fig. 3, it was found that genotypes 1-4 and 6 had higher Pro content at seedling stage under level 1 condition than that at tilling stage. Genotype 2 had the highest Pro content at seedling stage and it reduced to $60 \%$ at tilling stage. These genotypes all decreased in terms of Pro content from seedling stage to tilling stage, showing that they had reducing ability to regulate osmotic substances for drought resistance to soil water deficits with progression of development. This fact was similar to A group mentioned above. Genotypes 5 and 7-10 had higher Pro content at tilling stage at level 1 than that at seedling stage. Genotypes 7 and 9 had the highest Pro content at tilling stage at level 1. These genotypes all had increasing Pro content from seedling stage to tilling stage, which was contrary to the first five genotypes. This fact showed that the latter five genotypes had increasing ability to synthesize osmotic regulators (Pro) for protect from the damage of soil water deficits, which should belong to $\mathrm{B}$ or $\mathrm{C}$ group mentioned above.

\subsection{Proline content difference of 10 wheat genotypes for seedling and tilling stage under the condition of level 2}

According to Fig. 4, genotypes 1, 3, 7 and 8 had higher Pro content at seedling stage at level 2 than that at tilling stage. Genotypes 2, 4-6, 9 and 10 had higher Pro content at tilling stage than that at seedling stage. Genotype 9 had the highest 


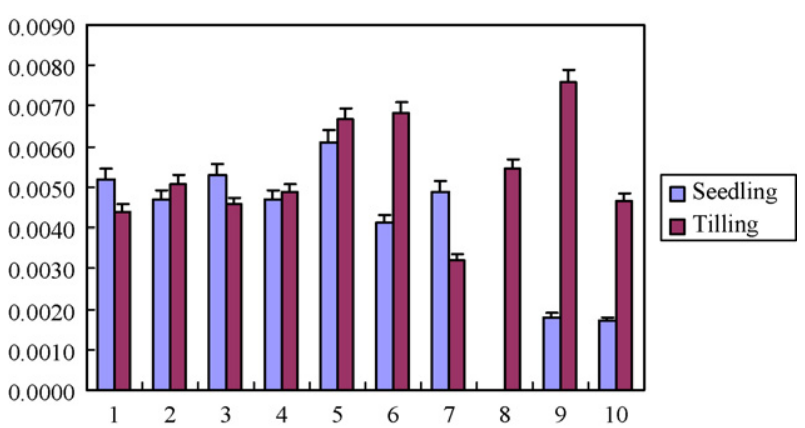

Fig. 4. The proline content $(\mu \mathrm{g} / \mathrm{g} \mathrm{dw})$ difference of 10 wheat genotypes for seedling and tilling stage under the condition of level 2.

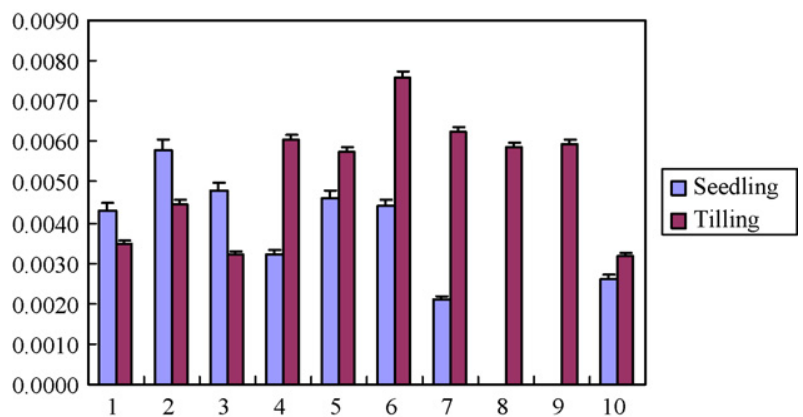

Fig. 5. The proline content $(\mu \mathrm{g} / \mathrm{g} \mathrm{dw})$ difference of 10 wheat genotypes for seedling and tilling stage under the condition of level 3. A 3.5 proline content difference of 10 wheat genotypes for seedling and tilling stage under the condition of level 3.

Pro content. These results indicated that with progression of soil water deficits (from levels 1 to 2) most genotypes expressed increasing anti-drought ability, which was also consistent with developmental pace.

From Fig. 5, it was found that at level 3, genotypes 1-3 had higher Pro content at seedling stage than that at tilling stage. Genotype 2 had the highest Pro content. These results demonstrated that the above genotypes performed better drought resistance at seedling than that at tilling stage under the condition of level 3 , which needed precise field water management for full physiological realization and better productivity. Genotypes 4-10 had higher Pro content at tilling stage than at seedling stage. Genotype 6 had the biggest Pro content among these genotypes at tilling stage at level 3 , showing that it had better anti-drought ability under the condition of severe soil water deficits and it perhaps had the lower soil water stress threshold. The above 7 genotypes exhibited better drought resistance potential at level 3 from seedling stage to tilling stage, implying that developmental course and soil water deficit level impacted on the expression of corresponding anti-drought-related genes, which would provide a valuable reference for molecular biology study and biotechnological breeding.

\section{Discussion}

Osmotic adjustment is the main component of physiological machinery, by which plants respond to soil water deficits $[8,15,24,36,38,44]$. Osmotic regulators include ions $\left(\mathrm{K}^{+}\right)$, small molecules (Pro), soluble sugar and others. Plants with higher osmotic regulators can absorb water from soil-water-deficit condition. In wheat, many reports showed that wheat cultivars with higher $\mathrm{K}^{+}$, Pro, soluble sugar and lower MDA at different growth stages performed better drought resistance $[2,5,6-8,11,24,36,59]$. Our experiments [Figs. 1-5] further proved such conclusion.

Our results firstly clearly showed that different wheat genotypes differently responded to soil water stress at different stages in terms of physiological mechanisms, implying that they have different soil water stress threshold (e.g. [56-58]). Exploring its range and accurate amount of different genotypes is of importance to understanding physiological mechanisms of wheat resistance and tolerance drought and saving-water agriculture by the way of physiological regulation in arid and semi-arid locations. Secondly, our experimental results further demonstrated the concept and method accepted and adopted by most scholars [24], that $75 \% \mathrm{FC}, 55 \% \mathrm{FC}$, and $45 \% \mathrm{FC}$ is normal, light-stressed, and severe-stressed water level, respectively, is needed to be modified in order to represent the practical level of more plants. As for different wheat genotypes, they have quite different soil water stress thresholds. In our experiment and under our experimental condition, genotypes 1-3 (divided into A group) may have higher soil water stress threshold and 4-10 (divided into B or C group) have lower soil water stress threshold (Figs. 1-5). Of course, soil water stress threshold for wheat with different genotypes can also be influenced by developmental course and physiological activities (e.g. POD and SOD CAT). Thirdly, we also found that the changing trend of Pro under our condition of three stress levels (Figs. 1 and 2) is tightly linked with the location of their cultivation, which reflects the change of corresponding alleles of different genotypes under the pressure of natural and artificial selection [7,17,35,47]. Moreover, this might be linked with evolution of wheat root systems $[8,38,39,41,47,68-72]$. This point is of importance to plant species selection for eco-environmental construction and crop selection for agricultural sustainable development in arid and semi-arid regions. Knowing the refine physiological nature, in conjunction with natural rainfall status of different locations, is very important to popularize new wheat species and conduct wheat breeding [49-54,73-85]. Fourthly, evaluating wheat drought resistance need many indexes as possible as one can. Moreover, measurement of these indexes through different growth-development stages is also necessitated. Our results demonstrated that Pro content (Figs. 1-5) was a better indice for evaluating wheat drought resistance $[11,18,47,71,74]$. Finally, our results primarily showed that genotypes 5, 9 and 10 were potential wheat genotypes for popularizing in arid and semiarid locations.

In a word, the study of physiological mechanisms of wheat anti-drought has much work to do. Molecular biology aspects of wheat cannot substitute for this important part, but can strengthen such research and provide a broad future and platform. It is easy to see that one cell or molecule cannot be alive in natural fields and not provide any economic effect for human beings [54-58,60]. The combination of molecular biology, plant physiology and other related disciplines (e.g. pedology) is the 
key. Many achievements in biotechnological and traditional breeding of wheat are good examples. Although some progresses in terms of the exploration of molecular nature of wheat antidrought also have taken place, many problems exist. Currently, from the view of globe, sustainable development is the key point. The necessary way to solve the issue of sustainable development is by biological measures, in which plants will play greater roles and crops will play the greatest functions with no doubt [60]. To aim at taking advantage of full use of crop physiological potential for high production and safe food with better quality, the followed problems remain to be known, which we have laid a stress on for many times in the former reports [52-58,73-85]. What is the relationship of mineral elements (in particular, $\mathrm{K}^{+} \mathrm{Na}^{+}$in soils) with root signal transduction (pathways)? What is the exact soil water stress threshold of individual wheat genotype? This is of much importance to resistance drought breeding and savingwater agriculture and precise agriculture under global climate change. What are the details that constitute the network regulatory system of drought, cold, UV-B, freezing, acidity, salty, wounding, pathogen, senescence, cell death? How is each linked with the other parts? What is the (transient)connection among different physiological adaptive regulatory pathways at different levels? What roles do endogenous hormones play in this course? What is the crosstalk among them when abiotic or/and biotic stress happens? The redox state in plants is important, and how is it regulated by drought signal? What is the best allocation of different crops and grass-shrub-forest in worsening arid and semi-arid areas for obtaining economic and ecological effect simultaneously? What is the co-relationship between LEA (late-embryogenesis abundant protein) and drought resistance of different wheat genotypes? A widespread use of data resources for fine gene functions and structure of different plants (species) is from model plants, Arabidopsis thaliana and rice, and how large is the reliability? No doubt, expanded detecting of plant range is more urgent. physiological studies at different scales have a long way to go with the increasing climate change.

\section{Acknowledgements}

Shao HB is grateful for the support from Initiation Foundation of Qingdao University of Science and Technology (QUST) (0022221), Chongqing University of Post\&Telecom (2005A92), Natural Science Foundation of Shandong Province(To Shao HB), and Talent Foundation of Laiyang Agricultural University (No. 630523) (To Zhao CX) and Natural Science Foundation of China (No. 40473054) (To Wu G).

\section{References}

[1] A. Andersson, J. Keskitalo, A. Sjodin, et al., A transcriptional time table of autumn senescence, Genome Biol. 5 (2004) R24-R37.

[2] K. Apel, A. Hirt, Reactive oxygen species: metabolism, oxidative stress, and signal transduction, Annu. Rev. Plant Biol. 55 (2004) 373-399.

[3] A. Anand, H.N. Gill, B.S. Trick, et al., Stable transgene expression and random gene silencing in wheat, Plant Biotechnol. J. 1 (4) (2003) 241-251.

[4] P. Casati, V. Walbot, Rapid transcriptome responses of maize (Zea mays) to UV-B irradiated and shielded tissues, Genome Biol. 5 (2004) R16-R28.
[5] Z. Chen, D.R. Gallie, The Ascorbic acid redox state controls guard cell signaling and stomatal movement, Plant Cell 16 (2004) 1143-1162.

[6] T. Capell, L. Bassie, P. Christou, Modulation of the polyamine biosynthetic pathway in transgenic rice confers tolerance to drought stress, PNAS 101 (26) (2004) 9909-9914.

[7] J.W. Chandler, D. Bartels, Drought avoidance and drought adaptation, Encyclopedia Water Sci. (2003) 163-165.

[8] M.M. Chaves, J. Maroco, J. Pereira, Understanding plant responses to drought-from genes to the whole plant, Funct. Plant Biol. 30 (2003) 239-264.

[9] S.A. Casson, K. Lindsey, Genes and signaling in root development, New Phytol. 158 (1) (2003) 11-34.

[10] J.C. Cushman, J. Bohnert, Genomic approaches to plant stress tolerance, Curr. Opin. Plant Biol. 3 (2) (2000) 117-124.

[11] S. Dhanda, G.S. Sethi, R.K. Behl, Indices of drought tolerance in wheat genotypes at early stages of plant growth, J. Agron. Crop Sci. 190 (1) (2004) 6-12.

[12] L.J. Dai, Z.Q. Li, Comparative and functional genomics of wheat, Acta Bot. Boreal-Occ. Sin. 24 (5) (2004) 949-953.

[13] European Commission, Plants for the future: a European vision for plant genomics and biotechnology towards, 2004, p. 2025 (see the web site: http://www.europabio.org/)

[14] Editor's choice, The National Plant Genomics Initiative: Objectives for 2003-2008, Plant Physiol. 130 (2002) 1741-1744.

[15] L. Erdei, I. Tari, J.I. Csiszar, et al., Osmotic stress responses of wheat species and cultivars differing in drought tolerance: some interesting genes (advices for gene hunting), Acta Biol. Szeged. 46 (3-4) (2002) 63-65.

[16] W. Fricke, G. Akhiyarova, D. Veselov, et al., Rapid and tissue-specific changes in ABA and in growth rate in response to salinity in barley leaves, J. Exp. Bot. 55 (399) (2004) 1115-1123.

[17] O. Fiehn, Metabolomics-the link between genotypes and phenotypes, Plant Mol. Biol. 48 (2002) 155-171.

[18] 4th International Crop Science Congress, 26 September-1 October, Brisbane, Australia, 2004

[19] C. Glombitza, P.H. Dubuis, O. Thulke, et al., Crosstalk and differential response to abiotic and biotic stressors reflected at the transcriptional level of effector genes from secondary metabolism, Plant Mol. Biol. 51 (2004) 1-19 (uncorrected proof).

[20] J.F. Gao (Ed.), Experimental Technology in Plant Physiology, World Books Publishing Company, Xi' an, China, 2000.

[21] J.A. Hernandez, C. Escobar, G. Creissen, et al., Role of hydrogen peroxide and the redox state of ascorbate in the induction of antioxidant enzymes in pea leaves under excess light stress, Funct. Plant Biol. 31 (4) (2004) 359-368.

[22] M.Y. Hiral, M. Yano, D.B. Goodenowe, et al., Integration of transcripomics and metabolomics for understanding of global responses to nutritional stresses in Arabidopsis, PNAS 101 (26) (2004) 1-6.

[23] H.P. Harding, Y.H. Zhang, H.Q. Zeng, et al., An integrated stress response regulates amino acid metabolism resistance to oxidative stress, Mol. Cell 11 (2003) 619-633.

[24] T.C. Hsiao, Plant response to water stress, Plant Physiol. 24 (1973) 519-534.

[25] Y.H. Li, W. Wang, Q.J. Ma, et al., The osmotic adjustment and photosynthesis of a wheat cultivar Hanfeng 9703 with high yield, drought resistance under drought stress, Acta Agron. Sin. 29 (5) (2003) 759-764.

[26] Y.S. Liu, S.I. Roof, Z.B. Ye, et al., Manipulation of light signal transduction as a means of modifying fruit nutritional quality in tomato, PNAS 101 (26) (2004) 9897-9902.

[27] X.N. Liu, W.M. Vance Baird, Identification of a novel gene, HAABRC5, from Helianthus annuus (Asteraceae) that is upregulated in response to drought, salinity, and abscisic acid, Am. J. Bot. 91 (2004) 184-191.

[28] S. Llesuy, P. Evelson, A.M. Campos, et al., Methodologies for evaluation of total antioxidant activities in complex mixtures, Crit. Rev. Biol. Res. 34 (2) (2001) 47-65.

[29] J. Kopka, A. Fernie, W. Weckwerth, et al., Metabolite profiling in plant biology: platforms and destinations, Genome Biol. 5 (2004) 109-125.

[30] H. Kitano, Looking beyond the details: a rise in system-oriented approaches in genetics and molecular biology, Curr. Genet. 41 (1) (2002) 1-10. 
[31] M. Kern, Food, feed, fibre, fuel and industrial products of the future: challenges and opportunities. Understanding the strategic potential of plant genetic engineering, J. Agron. Crop Sci. 188 (5) (2002) 291-302.

[32] M. Kasuga, Q. Liu, S. Miura, et al., Improving plant drought, salt, and freezing tolerance by gene transfer of a single-inducible transcription factor, Nat. Biotechnol. 17 (3) (1999) 287-291.

[33] J.A. Kreps, Y.J. Wu, H.S. Chang, et al., Transcriptome changes for Arabidopsis in response to salt, osmotic, and cold stress, Plant Physiol. 130 (2002) 2129-2141.

[34] M.Y. Jiang, J.H. Zhang, Abscisic acid and antioxidant defense in plant cells, Acta Bot. Sin. 46 (1) (2004) 1-9.

[35] R.L. Jing, X.P. Chang, Genetic diversity in wheat (T. aestivum) germplasm resources with drought resistance, Acta Bot. Boreal-Occ. Sin. 23 (3) (2003) 410-416.

[36] F.J.M. Maathuis, V. Filatov, P. Herzyk, et al., Transcriptom analysis of root transporters reveals participation of multiple gene families in the response to cation stress, Plant J. 35 (2003) 675-692.

[37] C. Mlot, Plant biology in the genome era, Science 281 (5375) (1998) 331-332.

[38] R. Munns, Comparative physiology of salt and water stress, Plant Cell Environ. 25 (2) (2002) 239-252.

[39] J.M. Morgan, Plants: osmotic adjustment, Encyclopedia Water Sci. (2003) 692-695.

[40] E. Mantyla, V. Lang, T. Palva, Role of abscisic acid in drought-induced freezing tolerance, cold acclimation, and accumulation of LT178 and RAB18 proteins in Arabidopsis, Plant Physiol. 107 (1995) 141-148.

[41] P. Neumann, Salinity resistance and plant growth revisited, Plant Cell Environ. 20 (1997) 1193-1198.

[42] F.X. Niu, X.X. Hua, X.D. Guo, et al., Studies on several physiological indexes of the drought resistance of sweet potato and its comprehensive evaluation, Acta Agron. Sin. 22 (4) (1996) 392-398.

[43] D. Patnaitk, P. Khurana, Wheat biotechnology: a minireview, EJB Electron. J. Biotechnol. 4 (2) (2001) 74-102.

[44] Z. Plaut, Crop plants: critical development stages of water, Encyclopedia Water Sci. (2003) 95-100

[45] A. Pellegrineschi, J.M. Ribaut, R. Trethowan, et al., Progress in the genetic engineering of wheat for water-limited conditions. JIRCAS Working Rep. (2002) 55-60.

[46] A. Rellegrineschi, J.M. Ribaut, N.R. Trethowan, et al., Looking beyond the details: a rise in system-oriented approaches in genetics and molecular biology, Curr. Genet. 41 (1) (2002) 1-10.

[47] J. Saba, M. Moghaddam, K. Ghassemi, et al., Genetic properties of drought resistance indices, J. Agric. Sci. Technol. 3 (2001) 43-49.

[48] X. Shou, P. Bordallo, K. Wang, Expression of the Nicotiana protein kinase (NPK1) enhanced drought tolerance in transgenic maize, J. Exp. Bot. 55 (399) (2004) 1013-1019.

[49] C. Somerville, J. Dangl, Plant Biology in 2010, Science 290 (4599) (2000) 2077-2078.

[50] K. Shinozaki, E.S. Dennis, Cell signaling and gene regulation global analyses of signal transduction and gene expression profiles, Curr. Opin. Plant Biol. 6 (5) (2003) 405-409.

[51] K. Shinozaki, K. Yamaguchi-Shinozaki, M. Seki, Regulatory network of gene expression in the drought and cold stress responses, Curr. Opin. Plant Biol. 6 (5) (2003) 410-417.

[52] H.B. Shao, Z.S. Liang, M.A. Shao, et al., Impacts of PEG-6000 pretreatment for barley (Hordeum vulgare L.) seeds on the effect of their mature embryo in vitro culture and primary investigation on its physiological mechanism, Colloids Surf. B: Biointerfaces 41 (2-3) (2005) 73-77.

[53] H.B. Shao, Z.S. Liang, M.A. Shao, LEA protein: structure, functions and gene expression, Colloids Surf. B: Biointerfaces 45 (3-4) (2005) 131135 .

[54] H.B. Shao, Z.S. Liang, M.A. Shao, Adaptation of higher plants to environmental stresses and stress signal transduction, Acta Ecol. Sin. 25 (7) (2005) $1772-1781$.

[55] H.B. Shao, Z.S. Liang, M.A. Shao, et al., Changes of some physiological and biochemical indices for soil water deficits among 10 wheat genotypes at seedling stage, Colloids Surf. B: Biointerfaces 42 (2) (2005) 107113.
[56] H.B. Shao, Z.S. Liang, M.A. Shao, Changes of some anti-oxidative physiological indices under soil water deficits among 10 wheat genotypes at tillage stage, J. Sci. Food Agric. 87 (6) (2006).

[57] H.B. Shao, Z.S. Liang, M.A. Shao, Changes of anti-oxidative enzymes and MDA content under soil water deficits among 10 wheat (Triticum aestivum $L$ ) genotypes at maturation stage, Colloids Surf. B: Biointerfaces 45 (1) (2005) 7-13.

[58] H.B. Shao, Z.S. Liang, M.A. Shao, Dynamic changes of anti-oxidative enzymes of 10 wheat (Triticum aestivum L.) genotypes at soil water deficits, Colloids Surf. B: Biointerfaces 42 (3-4) (2005) 187-195.

[59] Z.C. Tang, Responses and adaptation of plants to water stress, Plant Physiol. Commun. (4) (1983) 1-7.

[60] I.K. Vasil, The science and politics of plant biotechnology-a persona perspective, Nat. Biotechnol. 21 (8) (2003) 849-851.

[61] P. Wenzl, J. Carling, D. Kudrma, et al., Diversity arrays technology (DArT) for whole-genome profiling of barley, PNAS 101 (26) (2004) 9915-9920.

[62] W.X. Wang, P. Vinocur, A. Altman, Plant responses to drought, salinity and extreme temperatures: towards genetic engineering for stress tolerance, Planta 218 (1) (2003) 1-14

[63] S.W. Yu, K.X. Tang, MAP kinase cascades responding to environmental stress in plants, Acta Bot. Sin. 46 (2) (2004) 127-136.

[64] I. Yordanov, V. Velikova, T. Tsonev, Plant responses to drought and stress tolerance, Bulg. J. Plant Physiol. (2003) 187-206 (special issue).

[65] J.H. Zhu, H.Z. Shi, B.H. Lee, et al., An Arabidopsis homeodomain transcription factor gene, HOS9, mediates cold tolerance through a CBFindependent pathway, PNAS 101 (26) (2004) 9873-9878.

[66] J.K. Zhu, Salt and drought stress signal transduction in plants, Annu. Rev Plant Biol. 53 (2000) 247-273.

[67] J.K. Zhu, Regulation of ion homeostasis under salt stress, Curr. Opin. Plant Biol. 6 (5) (2003) 441-445.

[68] M. Zhiponova, L. Szilaz, L. Erdei, et al., Comparative approach for the isolation of genes involved in the osmotolerance of wheat, Acta Biol. Szeged. 46 (3-4) (2002) 73-75.

[69] J.X. Zhang, M.B. Kirham, Drought stress-induced changes in activities of superoxide dismutase, catalase, and peroxidase in wheat species, Plant Cell Physiol. 35 (5) (1994) 785-791.

[70] M.S. Zhang, Z.H. Peng, B. Xie, et al., Relationship between water loss rate of cutting leaves and osmotic regulators under water stress and drought resistance in sweet potato, Sci. Agric. Sin. 37 (1) (2004) 152-156.

[71] M.F. De Escalada Pla, N.M. Ponce, M.E. Wider, et al., Chemical and biochemical changes of pumpkin (Cucumis moschata, Duch) tissue in relation to osmotic stress, J. Sci. Food Agric. 85 (11) (2005) 1852-1860

[72] V.S. Conceicao, I.P. Falcao, G.C. Pinto, et al., Nutrient responses and glutamate and proline metabolism in sunflower plants and calli under $\mathrm{Na}_{2} \mathrm{SO}_{4}$ stress, J. Plant Nutr. Soil Sci. 165 (3) (2002) 366-372.

[73] H.B. Shao, Z.S. Liang, M.A. Shao, S.M. Sun, Z.M. Hu, Investigation on dynamic changes of photosynthetic characteristics of 10 wheat (Triticum aestivum L.) genotypes during two vegetative-growth stages at water deficits, Colloids Surf. B: Biointerfaces 43 (3-4) (2005) 221-227.

[74] H.B. Shao, M.A. Shao, Z.S. Liang, Osmotic adjustment comparison of 10 wheat (Triticum aestivum L) genotypes at soil water deficits, Colloids Surf. B: Biointerfaces 47 (2) (2006) 132-139.

[75] Y. Tan, Z.S. Liang, H.B. Shao, Effect of water deficits on the activity of anti-oxidative enzymes and osmoregulation among 3 different genotypes of Radix Astragali at seeding stage, Colloids Surf. B: Biointerfaces 49 (1) (2006) 60-65.

[76] L.Y. Chu, H.B. Shao, M.Y. Li, Molecular biological mechanisms of photochrome signal transduction, Colloids Surf. B: Biointerfaces 45 (3-4) (2005) 154-161.

[77] G.R. Sun, Y.Z. Peng, H.B. Shao, L.Y. Chu, Does Puccinelia tenuiflora have the ability of salt exudation? Colloids Surf. B: Biointerfaces 45 (5) (2005) 207-213.

[78] H.B. Shao, Z.S. Liang, M.A. Shao, New considerations for improving ecoenvironment: take advantage of information timely and efficiently from molecular biology and biotechnology, J. Chongqing Uni Posts Telecom (Nat. Sci. Ed.) 16 (4) (2004) 95-99.

[79] H.B. Shao, L.Y. Chu, Plant molecular biology in china: opportunities and challenges, Plant Mol. Biol. Rep. 23 (4) (2005) 345-358. 
[80] H.B. Shao, L.Y. Chu, M.A. Shao, Some advances in plant stress physiology and their implications in the systems biology era, Biointerfaces 51 (3) (2006).

[81] M. Ashraf, M.R. Foolad, Roles of glycine betaine and proline in improving plant abiotic stress, Environ. Exp. Bot. 55 (2006).

[82] H. Philippe, R.G. George, J.G. Peter, et al., Rhizosphere geometry and heterogeneity arising from root-mediated physical and chemical processes, New Phytol. 168 (2005) 293-303.
[83] R. Munns, Genes and salt tolerance: bringing them together, New Phytol. 167 (2005) 645-663.

[84] X.A. Liu, D.R. Bush, Expression and transcriptional regulation of amino acid transporters in plants, Amino Acids (1) (2006) 1-8.

[85] H.B. Shao, L.Y. Chu, C.X. Zhao, Q.J. Guo, X.A. Liu, L. Erdei, Plant gene regulatory network system under abiotic stress, Acta Biol. Szeged. 50 (1-2) (2006) 1-9. 